\title{
Factors Affecting Human Capital in Singapore
}

\author{
S M Nazmuz Sakib \\ Graduate of BSc in Business Studies \\ School of Business And Trade \\ Pilatusstrasse 6003, 6003 Luzern, Switzerland \\ sakibpedia@gmail.com \\ Student of Department of Law \\ Dhaka International University \\ House \# 4, Road \# 1, Block - F, Dhaka 1213 \\ sakibpedia@students.diu.ac \\ Student of BEcon in Environmental and Resource Economics \\ Dhaka School of Economics \\ 4/C Eskaton Garden Rd, Ramna, Dhaka 1000, Bangladesh. \\ sakib.bee5@dsce.edu.bd
}


Factors affecting Human capital in Singapore

\begin{abstract}
The human capital index is a multivariate variable used to measure the assessment of human resource productivity in the future. Human capital has a connection with economic development. Moreover, the study looks to analyses the relationship between Human Capital and Economic Growth indicators such as HCI and GDP. Human Capital relates to the development of individual skills to make them function more profitable for the national economy. The study was aimed at investigating the effect of population, the number of people engaged and the average annual hours worked by engaged persons on the human capital index. The analysis was in SPSS for the findings. Correlation tests were used for analysis. The study revealed that population, the number of people engaged and the average annual hours worked by engaged persons had a significant positive effect on the human capital index.
\end{abstract}

\title{
Keywords
}

Human Capital, Human Capital Management, Human Capital Factors, Affecting Factors in Human Capital, Human Capital in Singapore 
Factors affecting Human capital in Singapore

\subsection{Introduction}

Singapore is one of the countries that encourages the development of its human capital through collaboratively planned and structured education, training, and policies. The country has no natural resources, however, it considers human resource as its most important strategic capital (Osman-Gani, 2004)1. Singapore has been ranked as the top country in the Human Capital Index. Consequently, the strength of human capital in Singapore may have a positive role in Economic growth. Several decades ago, Singapore had a low-skilled human resource and high incidences of tropical diseases. However, Singapore has now transformed its human resource into a highly skilled force. In addition Singapore found remedies for the tropical diseases. Therefore, Singapore is regarded as the best-performing state by the World Bank Human Capital Index (Global Delivery Initiative, 2020) ${ }^{2}$. This study views development of Human Capital in Singapore from the perspective of economics, econometrics, and human resource management perspectives

\section{Human Capital Index in Singapore}

Human Capital Index (HCI) is the assessment of human knowledge, skills, and health. The factors that influence assessment of the HCI range child mortality rate, expected level of education, grades, adult survival rate, and stunted growth among children. According to Kraay (2018) the

\footnotetext{
${ }^{1}$ Osman-Gani, A. M. (2004 ). Human Capital Development in Singapore: An Analysis of National Policy
} Perspectives. Advances in developing human resources.

${ }^{2}$ Global Delivery Initiative. (2020). Integrating Human Capital into National Development Planning in Singapore. 
Factors affecting Human capital in Singapore

assessment of HCI ranges from 1 being the best and zero being lowest level of human capital productivity. The theory proposed by Kraay $(2018)^{3}$ suggests that HCI reflects the future productivity of a child born today given that he/she attained complete education and good health. According to the Human Capital Index $(2018)^{4}$, keeping all other factors constant, Singapore HCI score was 0.88 which was much better than other regional countries. The HCI score suggest that a baby born in 2018 in Singapore would be 88 percent productive by the time she grows up. Moreover, each and every child out of a 100 is expected to survive till age 5 . When the child reaches 18 years of age in Singapore, he/she would have acquired 13.9 years of education. The students in Singapore express positive significant performance in educational assessments. Interestingly, there is no evidence stunted growth among children in Singapore. Globalization urges developing economies utilize human resources as a capital to address economic issues. Dependence on a low-altitude, low-wage upper hand is dangerous because nations with even less developed economies will undermine neighboring states. The relationship between human resource and economic development, is correlated to human skill development.

\subsection{Purpose of the Study}

Singapore is an important case to analyze the factors that influence Human Capital development and also assess its influence on economic growth. Technical Education and Skill

\footnotetext{
${ }^{3}$ Kraay, A. (2018). Methodology for a World Bank human capital index. The World Bank.
} 
Factors affecting Human capital in Singapore

development are two important aspects of economic development and improvement. It is essential to assess skills and productivity of individuals to enable researchers and scholars to better

4 understand and suggest innovative learning programs for skill specialization. To encourage such specialized advancement would require a complex arrangement of supporting organizations and institutions, in addition to economic requirements (Gopinathan, 2006) ${ }^{4}$. There is a general understanding that the basic factors deciding the pattern of development one needs to identify major sectors where investment is made and physical capital is accumulated. The level of human resource development determines human capital as an asset which determines the efficiency of economic growth (Wong, 1981) ${ }^{5}$.

Human capital refers to the productivity of human resource, and increase in the salary as result of enhanced productivity, whereas economists view increase in salary as a driver of economic growth. Capital is a stock that has prospects for present and future progression of

${ }^{4}$ Gopinathan, S. (2006). Preparing for the Next Rung: economic restructuring and educational reform in Singapore. Journal of Education and Work, 295-308.

${ }^{5}$ Wong, P.-w. L.-c. (1981). Human Capital and Inequality in Singapore. Economic Development and Cultural Change. 
Factors affecting Human capital in Singapore

dividends and return on investment. Similarly, the Human capital is associated with the supply of aptitudes and profitable information which comprises knowledge, skills, and the ability to perform complex tasks efficiently (Paul A. David, 1975) ${ }^{6}$. To increase economic return on investment in human capital lies in improving skills, and learning abilities of the work force (human capital). Moreover, the investment in human resource will contribute to expanding economic productivityand also increase export of skilled human resource. Consequently, the export of human capital will increase the country's remittances which has a significant impact on economic growth. Maybe the fundamental arrangement zone where human capital is significant is openly arranging training and skill development programs for poor people. The rationale of these strategies lay on the suggestion that an individual's pay in a market economy mirrors the nature of assets that the individual controls and the estimation of these assets. Poor Individuals have limited skills and knowledge in comparison with the non-poor (Almendarez, 2013) ${ }^{7}$. Research suggests that education is a factor that determines economic growth and Human capital. Almendarez (2013) finds that economic growth and development requires education with good quality.

\footnotetext{
${ }^{6}$ Paul A. David, N. S. (1975). Technical Choice Innovation and Economic Growth: Essays on American and British Experience in the Nineteenth Century. Cambridge University Press.

${ }^{7}$ Almendarez, L. (2013). Human capital theory: Implications for educational development in Belize and the Caribbean. Caribbean Quarterly, 59(3-4), 21-33.
} 
Factors affecting Human capital in Singapore

This shows that development does not solely depend upon the nature of the political system adopted in the country. To investigate, it is not necessary to study development under dictatorial or democratic rules, rather the change in the long run development may delay under majority rule government. For every one of these reasons, developing nations ought to recognize the significance of Human Resource as the most important asset for development. Data for various economic, political, social, and development indicators can be accessed online from data banks and centres (Raut, 1997) ${ }^{8}$.

The majority of employees are domestic workers. However, the issue of lack of human resource capital can be solved by allowing human resource acquisition from other countries to

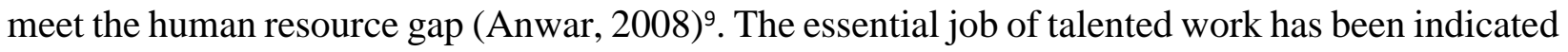
over and over when advanced mining, barrier or assembling hardware fell into deterioration and neglect because the workforce of developing nations had not gained the fundamental aptitudes for its activity and upkeep. Economic departments and institutions in the developing state need to policies to increase education opportunities and to train the workers. Learned and skilled workers

${ }^{8}$ Raut, A. L. (1997). Complementarities between Exports and Human Capital in Economic Growth: Evidence from the Semi-industrialized Countries. Economic Development and Cultural Change.

${ }^{9}$ Anwar, S. (2008). Foreign investment, human capital and manufacturing sector growth in Singapore. Journal of Policy Modeling, 447-453. 
Factors affecting Human capital in Singapore

are increasingly profitable because they can utilize capital to ensure effectiveness, embrace innovations and learn from these combining concepts.

For efficient and comprehensive learning in science, construction, development and medical sectors, individuals often explore and study the experiences of other countries by visiting them and bring back new knowledge, skills, and ideas to the home country. However, sometimes these individuals do not come back and utilize their knowledge, skills, and ideas in their home country; rather, they prefer to say abroad due to high-wages offered there. Such kind of concept is termed as "brain drain". Economic growth and development have a significant association with human capital. Subsequently, human capital also has an impact on economic growth due to individuals having the ability to learn new information and skills (Sam, 2008) ${ }^{10}$.

\subsection{Objectives of the study}

- To determine the most important cause of Singapore's capital formation.

- To determine the importance of human capital for Singapore's economic growth.

- To determine the impact of the population of persons in Singapore on the human capital index

- To determine the impact of the number of persons engaged (in millions) in Singapore on the human capital index

${ }^{10}$ Sam, S. A. (2008). Services sector growth in Singapore. Singapore Institute of Management. 
Factors affecting Human capital in Singapore

- To determine the impact of the average annual hours worked by the engaged persons in Singapore on the human capital index

\subsection{Research Questions}

- What caused, and was most important for Singapore's human capital formation?

- How important is human capital to Singapore's economic growth?

- What is the impact of the population of persons in Singapore on the human capital index?

- What is the impact of the number of persons engaged (in millions) in Singapore on the human capital index?

- What is the impact of the average annual hours worked by the engaged persons in Singapore on the human capital index? 
Factors affecting Human capital in Singapore

\section{Chapter 2.0 Literature review}

\subsection{History of Singapore}

Since autonomy in 1965, Singapore's economy has travelled from a low-pay economy to a high-pay created economy. Over the period, the instructive strategy of the nation has been encircled reliable with the national monetary arrangement and human capital development (Chan, 2009) ${ }^{11}$. While Jamaica picked put its assets in the agrarian and mining ventures (alongside the travel industry), Singapore picked an alternate course. It concentrated on the significance of training and created a trend-setting innovation. The two results, as far as thriving and way of life, show which course was ideal. Today Singapore's GDP per capita is more than multiple times the degree of Jamaica's.

${ }^{11}$ Chan, A. M. (2009). Trends and challenges of developing human capital in Singapore: an analysis of current practices and future potentials. Human Resource Development International. 
Factors affecting Human capital in Singapore

Moreover, Singapore holds the thirteenth position in the world for taking positive steps towards instruction and social insurance as estimations of its pledge to economic development, as per the major ever logical analysis positioning nations for their degrees of human capital.

Singapore's positioning of thirteenth in 2016 speaks to a significant improvement from its 1990 positioning of $43^{\text {rd }}$ (Garcia-Zamor, 2017) ${ }^{12}$.

It originates from having 24 years of anticipated human capital, estimated as the number of years an individual can be relied upon to work in the long periods of pinnacle efficiency, considering future, good wellbeing, long periods of tutoring, and learning. Pondering human capital turn of events, and the board is the soul of most high-performing organizations and associations. Government-funded training in this country ought to be the same. Principals' and instructors' presentations have more impact on understudy accomplishment than some other factors, and their adequacy in expanding understudy execution generally fluctuates. Given the stakes, it is basic to follow up on that information and fortify the training workforce to all the more likely serve understudies. As one of the most emerging countries of Asia, Singapore is prominent for its vibrant and resourceful human capital expansion events. These are motivated basically by the management activities, with assistance from undefended zone associations and gigantic area

\footnotetext{
${ }^{12}$ Garcia-Zamor, A. S.-C. (2017). Influence of Human Capital on Economic Growth: A Comparative Analysis of Education Development in Kazakhstan, South Korea, Singapore and Malaysia. Journal of Public Administration and Governance.
} 
Factors affecting Human capital in Singapore

organizations. Human asset improvement (HRD) related enactments, monetary motivations, infraauxiliary help and sending of the board and information correspondence advances (ICT) help to support the national HRD activities $(\mathrm{Ge}, 2011)^{13}$.

The endeavour to give this by giving a case history examination of Singapore in three phases of development - as a port city, mechanical city and as a world city - to show how the advancing framework related with human capital (training, movement and work approaches) permits human money to be created, pulled in, bridled, sent, discharged and held. This paper researches the since a long time ago run and the short-run elements among the travel industry and financial development in Singapore. Utilizing the limits test created by Pesaran et al. (2001), cointegrating connection among the travel industry and financial development is not found. The standard Granger causality test uncovers that there is a unidirectional Granger causality from financial development to the travel industry (Huff, 1997) ${ }^{14}$.

The development bookkeeping results propose that hardware imports joined with human capital stocks have a positive and factually firmly critical effect on cross country development.

${ }^{13} \mathrm{Ge}$, K. C. (2011). Education and human capital management in a world city: the case of Singapore. Asia Pacific Journal of Education, 263-276.

${ }^{14}$ Huff, W. G. (1997). The economic growth of Singapore: Trade and development in the twentieth century. Cambridge University Press. 
Factors affecting Human capital in Singapore

This contrasts with the change to the consistent state. This offers to back to initial discoveries in writing, which propose that the main job of human capital in financial development is to encourage the appropriation of innovation from abroad, rather than to go about as an autonomous factor of creation. Singapore gives an intriguing contextual analysis of human capital turn of events (HCD) as national methodology. Its human asset procedures have been ceaselessly modified and balanced related to other national key financial approaches. Albeit a few examinations have been done on micro-level human asset advancement (HRD) rehearses, almost no exploration has been done on the key and macro-level approach points of view. This article presents an examination of macrolevel HCD systems in Singapore from a national approach viewpoint and portrays the components of the HRD framework. Generally, hypotheses of monetary development are to show the idea of the exogenous factors which eventually decide the rate at which the general degree of creation of an economy is developing, and in this manner add to a comprehension of the subject of why a few social orders become such a great amount of quicker than others (LEE, 2008) ${ }^{15}$.

The time arrangement estimates to the development paces of genuine yield, profitability and interest in the Singaporean assembling area. Looking into advanced transnational education under understudy portability would, in general, barely present hard insights on understudy versatility, breaking down these as far as 'patterns' and the suggestion this has on strategy and internationalizing methodologies. What is absent from this 'enormous picture' is a nearby

${ }^{15}$ LEE, C. G. (2008). TOURISM AND ECONOMIC GROWTH: THE CASE OF. Regional and Sectoral Economic Studies. 
Factors affecting Human capital in Singapore

examination of the micro-politics of understudy versatility in explicit land settings. Despite a growing college area in Singapore, there is a diligent pattern of Singaporean understudies leaving the nation for abroad investigation, representing a potential issue of mind channel. This presents a socio-politico examination of understudy portability and the chaperon governmental issues this has made for Singapore's human capital structure (Maynes, 2011) ${ }^{17}$.

However, the Singapore case is clarifying about how to deals with its human perimeter building versus its outward-bound understudy transferability. Although there are 'strategies of mediation' set up, it is not clear how the Singaporean government handles two national predicaments identified with the socio-politico results of understudy portability. As indicated by Borjas (1995), the government assistance effect of outside specialists or migration surplus is characterized as the expansion in the pay of the local populace in the host nation because of movement.

Thus, the present paper observes the consequence of employees on the growth of the Singapore economy by building an exclusive general balance model of Drinkwater, Levine, Lotti and Pearlman (2007). The model represents the progression of talented and incompetent outside specialists on (a) consistent state development, (b) wage hole between the gifted and untalented, and (c) advancement abilities of the local economy. Further, the model likewise represents the commitment of foreigners on the government assistance of the local economy through the movement surplus that will gather to the household economy. 
Factors affecting Human capital in Singapore

${ }^{17}$ Maynes, G. (2011). Human capital accumulation: a comparative study of Singapore and Malaysia 1975 to 2006. Economics, Finance and Marketing, RMIT University.

On the other hand, State-of-the-art development has been a substantial section of the monetary turn of events in Singapore and Malaysia. Starting in the 1970s, Malaysia and Singapore experienced monetary change by effectively pulling in remote direct ventures into their cuttingedge, producing segments (Nguyen, 2009) ${ }^{16} . \mathrm{S}$

\subsection{Human capital theory in Singapore}

According to the World Economic Forum (WEF), Singapore has been positioned top in Asia for creating human capital. It positions eleventh out of 130 nations, having created 73 percent of its human capital as estimated by WEF's Human Capital Index. This makes Singapore the most elevated put Asian country. The just another country from the area in the best 20 in Japan, positioned seventeenth. The Global Human Capital Index 2017 positions 130 nations on how well they are building up their human capital across four measurements - limit, organization, improvement and ability - just as across various age gatherings. Moreover, the report found that the world has grown just 62 percent of its human capital, as estimated by the file. By and large, 38 percent of their ability. The United States and Germany are among the best-performing countries

\footnotetext{
${ }^{16}$ Nguyen, T-A. (2009). Sources of Economic Growth: Physical capital, Human Capital, Natural Resources, and TFP. Economics and Finance.
} 
Factors affecting Human capital in Singapore

in the best ten overwhelmed by littler European nations (Anwar, Manufacturing Sector Growth: A Case Study of Singapore, 2007) ${ }^{1718}$.

To clarify this hole among hypotheses and empirics, more spotlight has been laid on estimation blunder and information quality. Utilizing an elective gauge of the supply of human capital, in light of Judson (2002), we discover proof that the two significant perspectives on the job of human capital in financial improvement by Lucas (1988) and Romer (1990) exist together and are in no way, shape or form fundamentally unrelated. Utilizing a Johansen cointegration test, we find that in India and Indonesia, the degree of human capital is cointegrated with the degree of total pay during the entire twentieth century, which affirms Lucas's hypothesis (1988). In Japan, in any case, the Lucasian approach can be confirmed distinctly for the main portion of the century. At the same time, after 1950, there is cointegration between the development pace of total salary and the degree of human capital, which is by Romer's view (Eng, 2010) ${ }^{19}$.

Whether interest in human capital and business added to monetary development in Singapore over the last three decades, it has been examined. Johansen co integration tests locate a

${ }^{17}$ Anwar, S. (2007). Manufacturing Sector Growth: A Case Study of Singapore. Global Economic Review, $18-396$.

${ }^{19}$ Eng, V. M. (2010). Financial development and economic growth in Singapore: demand-following or supply-leading? Applied Financial Economics, 391-404. 
Factors affecting Human capital in Singapore

since a long time ago, the run connection among financial development, human capital speculation and utilized work power. The article also inquires the elements of financial development that kept up with human capital speculation and work power business, including a battery of econometric strategies. It is discovered that both human capital speculation and business add to ascend in financial development. Human capital speculation at the underlying stage has impending development impact and, in the end, quickens supported development with an incubation slack of 4 years (G. Agiomirgianakis, 2002) ${ }^{20}$.

On the off chance that the kept up connection persevered after some time, the study shows that human capital advancement would prompt an interminable ascent in monetary development. Work power business advancement, in such manner, may prompt a brief ascent in monetary development. Remote speculation has been for some time viewed as the primary driver of Singapore's assembling division development. Additionally, utilizing yearly information for the period 1980-2005, this paper contends that notwithstanding outside speculation, human capital is additionally assuming a critical job in foresting producing part development in Singapore. Observational investigation shows that outside venture, human capital and worth included assembling are co integrated. The paper likewise contends that proceeded with development into

\footnotetext{
${ }^{20}$ G. Agiomirgianakis, D. A. (2002). Human capital and economic growth revisited: A dynamic panel data study-international Advances in Economic Research, 177-187.
} 
Factors affecting Human capital in Singapore

the future requires further expansion of the assembling area and expanded spending on R\&D and propelled training (Sclafani, 2008) ${ }^{21}$.

The investigations give proof to help development drove the travel industry theory. This paper looks at new improvements in the worldwide and provincial economy as we arrive at the finish of just about two and a half many years of high financial development in Singapore, in the midst of a circumstance of monetary emergency and absence of trust in East Asia. It evaluates the idea of the progressions currently being brought into the Singapore instruction framework to envision the interest for imaginative and gifted work in the following thousand years. We analyze the job of human capital experimentally and worldwide and household advances, in the development of joblessness in Singapore. The outcomes show a limited level of human capital, beneath (above), which expands (diminishes) in human capital will lessen (raise) joblessness. This non-monotonic relationship is brought about by a more prominent replacement from work toward innovation possible at more significant levels of human capital. This paper examines the patterns of outside foreigners in Asia and their impact on the development of the Singapore economy $\left(\right.$ JUSTMAN, 2002) ${ }^{22}$.

${ }^{21}$ Sclafani, S. (2008). I am rethinking Human Capital in Education: Singapore as a Model for Teacher
Development. Aspen Institute.

22 JUSTMAN, M. G. (2002). Education, Social Cohesion, and Economic Growth. THE AMERICAN ECONOMIC REVIEW. 
Factors affecting Human capital in Singapore

To grow more speculations of worldwide efficiency contrasts. At long last, to gather point by point, nation information bearing on the procedure of innovation dispersion. Hypothetical advancements that stress the focal job of human capital in financial development have prompted expanded energy about the degree to which instruction adds to development, yet may have onesided our comprehension of the idea of its commitment. A general accentuation on the instrumental job of instruction in transmitting information minimizes its impact on development through its job as a mingling power. In this paper, we look for a superior comprehension of this job as it bears on the positive political economy of open tutoring and development, and on regulating investigations of training frameworks in multicultural social orders. The first is to see training as an interest in human capital (Koh, 2012) ${ }^{23}$.

Business analysts are not consistent in recognizing powers behind these high development rates. Hypothetically and experimentally, these discussions spur us to investigate more experiences in the collaborations between those basic powers to be specific: human capital, innovation, common assets, and learning-by-doing with monetary development. Those connections are most certainly not just mulled over in the consistent state yet overall powerful development process. However, ongoing experimental research on the empirics of development has shown that an expanded Solow model gives a genuinely decent depiction of cross country information on yield per specialist. Re-assessing this model by utilizing an intermediary for a load of human capital

${ }^{23}$ Koh, A. (2012). Tactics of Interventions: Student Mobility and Human Capital Building in Singapore. Higher Education Policy, 191-206. 
Factors affecting Human capital in Singapore

instead of a stream measure, I discover a considerably higher portion of human capital in pay than MRW. Given the current information, this outcome doesn't appear to experience the ill effects of asynchronous condition inclination. The MRW result doesn't appear to experience the ill effects of estimation mistakes. A changed expanded Solow model is recommended to accommodate the contending observational assessments (Leeuwen, 2008) ${ }^{24}$.

For a salary portion of physical capital of around $1 / 3$, the ramifications of this new development model are that the effect of human capital arrangement on yield per specialist is twice as high as the positive effect of physical capital arrangement and the negative effect of populace development. The MRW model is less idealistic in this regard: The effect of human and physical capital aggregation is anticipated to be the equivalent, and just half as extensive as the negative effect of populace development. This investigation expects to decide the since quite a while ago run effect of physical and human capital on GDP by utilizing the informational board index of 13 created and 11 creating nations over the period 1970-2010. The net fixed capital arrangement is utilized as a physical capital marker while instruction uses and future during childbirth are utilized as human capital pointers. Board DOLS and FMOLS board co integrated relapse models are abused to identify the size and indication of the co integration relationship and think about the impact of

\footnotetext{
${ }^{24}$ Leeuwen, P. F. (2008). Human Capital and Economic Growth in Asia 1890-2000: A Time-series Analysis
}

*. Asian Economic Journal, 225-240. 
Factors affecting Human capital in Singapore

these physical and human capital factors as per these two distinctive nation gatherings (Magnus Blomstrom, 2002) ${ }^{25}$.

As a result of boards DOLS and FMOLS models, the effect of physical capital and training consumptions on GDP in the created nations is resolved as higher than the effect in the creating nations. Then again, the effect of the future during childbirth on GDP is resolved as higher in the creating nations. This paper looks at the job of human capital on monetary development. Given the cross-sectional character in the majority of the applicable examinations, there is a likelihood that when the since quite a while ago run elements are thought of, instruction probably won't be a huge determinant of development. Following a unique board information approach, the examination shows that instruction has, in fact, a huge and positive since quite a while ago run impact on financial development. Besides, the size of this impact is more grounded as the degree of training (essential, auxiliary, and tertiary) increments. This has direct approach ramifications that legislatures taking activities towards an extension of their advanced education may well anticipate bigger gains as far as higher financial development in their nations (Maitra, 2016 ) ${ }^{2627 .}$

${ }^{25}$ Magnus Blomstrom, A. K. (2002). GROWTH AND INNOVATION POLICIES FOR A KNOWLEDGE ECONOMY: EXPERIENCES FROM FINLAND, SWEDEN, AND SINGAPORE. Stockholm School of Economics.

${ }^{26}$ Maitra, B. (2016). Investment in Human Capital and Economic Growth in Singapore. SAGE Journals, $27-437$. 
Factors affecting Human capital in Singapore

Since the capacity to improve will assume a progressively conspicuous job in driving future monetary development, the national legislatures of both Singapore and Malaysia have quickened arrangement endeavours planned for reinforcing their national development frameworks. These endeavors incorporate the acquaintance of wide measures with improving execution in zones like R\&D, instruction, innovative movement and information streams - which are all key determinants for imaginative movement (Osman-Gani, 2004$)^{28}$.

\subsection{Workforce Conditions and practices in Singapore}

The researchers have frequently found interest in training because of a lack of a spotlight on long-lasting learning and a mix of aptitudes required for entering and prevailing in the work showcase. In nations which have been the best at drawing on their kin's ability -, for example, Switzerland and Singapore - the vast majority work in high-talented and aptitude based occupations and do as such inside an unpredictable, expanding economy. Singapore joins the world's second-most noteworthy extent of high-talented work with huge qualities like its instruction framework and staff preparing, the report noted. Key zones for development incorporate boosting work power cooperation rates among more established specialists and getting more ladies into work - the nation positions 60 or lower for its work sexual orientation hole in

${ }^{28}$ Osman-Gani, A. M. (2004 ). Human Capital Development in Singapore: An Analysis of National Policy Perspectives. Advances in developing human resources. 
Factors affecting Human capital in Singapore

allimportant age sections. There is a general agreement that human capital is the main consideration behind since quite a while ago runs monetary development. However, on a full-scale level, the exact outcomes don't generally agree with this view (Briscoe, 2004) ${ }^{29}$.

Henceforth, the investigation of the present practices and future patterns and difficulties looked by associations in Singapore. A portion of these difficulties is maturing workforce, ability maintenance and improvement, quick, innovative changes and culturally diverse aptitudes advancement for working in the developing markets. Eight patterns and moves distinguished here are relied upon to affect altogether the HRD calling in the future. Ramifications of the patterns and difficulties are additionally talked about for future research and expert practice. To a great extent, Singapore's monetary achievement has been energized by a remote direct venture from global enterprises (MNCs). These organizations carried with them their capital and innovation, yet in addition to their administrative ability. The last has been a key fixing in pushing Singapore to its current monetary achievement. New rivalry and increasing expenses are driving nearby organizations to search for new techniques to succeed. One path is to benchmark the human capital methodologies of MNCs. This examination utilizes a review of the human asset strategies of both MNCs and promising Singaporean endeavors. The outcomes show obvious differentiations in the philosophical and common sense utilization of human asset procedures. Bits of knowledge into Singapore's human asset rehearses are revealed, and key achievement factors for promising nearby organizations are discussed. Two contending speculations in regards to the monetary turn of events

${ }^{29}$ Briscoe, R. A. (2004). The impact of human capital on economic growth: a review. Jour. 
Factors affecting Human capital in Singapore

and financial development are observationally explored, with regards to flexibly driving and request following the money (Gerald Z.D. Huang, 2002) ${ }^{30}$.

In addition, various research have examined the existence of the Singaporean assembling part, none of the accessible analyses has particularly believed about the Singaporean administration section. The primary determinants of the Singaporean administrations part esteem included have been analyzed. It utilizes board information that covers four significant administration enterprises from 1984 to 2004. Exact investigation proposes that administrations part work, human capital, and the development pace of GDP have a hugely beneficial outcome on the administration's area esteem included and surreptitiously fixed impacts are available over the chosen ventures. The paper likewise considers board cointegration. It is demonstrated that assembling area esteem included, business and human capital are co integrated. The assessed vector mistake remedy model recommends that change in accordance with the since a long time ago run harmony is genuinely moderate (Tan A. M., 2006) ${ }^{31}$.

The key work showcase patterns and the basis for remote specialists in a little open economy like Singapore. Further, the paper features key recreations of the effect of remote

${ }^{30}$ Gerald Z.D. Huang, M. H. (2002). MNCs in Singapore. Benchmarking: An International Journal.

${ }^{31}$ Tan, A. M. (2006). Human resource development: the key to sustainable growth and competitiveness of Singapore. Human Resource Development International, 417-432. 
Factors affecting Human capital in Singapore

outsiders on yield development and pay hole for the Singapore economy by utilizing Thangavelu's (2011) powerful broad balance model. The examination represents the progression of talented and incompetent outside specialists on (a) consistent state development; (b) the compensation hole between the gifted and untalented labourers; and (c) advancement abilities of the local economy. Further, the model additionally represents the commitment of foreigners on the government assistance of the residential economy through the movement surplus that will collect to the household economy (Tan K. W., 2008) ${ }^{32}$.

An alternate perspective on the job of training in financial achievement is that instruction has positive externalities; teach some portion of the network and its entire advantages. The possibility that instruction creates positive externalities is in no way, shape or form new. Smith (1976) reflected such a dynamic contemporary idea when he composed that by teaching its kin, a general public gets no negligible bit of margin from their guidance. The more they are informed and trained, the less at risk they are to the dreams of energy and odd notion, which, among oblivious countries, much of the time event the most frightening issue. Taught and astute individuals are, in every case, more methodical than oblivious ones. Smith sees the externalities to training as imperative to the best possible working of the economy as well as of a just society. This paper (I) utilizes a recently built dataset on hardware imports from both created and creating nations with

\footnotetext{
32 Tan, K. W. (2008). Nonmonotonic relationship between human capital and unemployment: an exploratory study with empirical evidence on Singapore. Applied Economics Letters, 1177-1185.
} 
Factors affecting Human capital in Singapore

noteworthy residential $R \& D$ use to evaluate innovation move to creating nations, and (ii) utilizes a cross country, development bookkeeping structure to break down the effect of apparatus imports, in relationship with human capital stocks, on financial development. The discoveries recommend that apparatus imports by creating nations have been higher over the past not many years than during the 1970s and 1980s and that such imports from mechanically more propelled creating nations have picked up significantly insignificance (Thangavelu, 2012) ${ }^{33}$.

\subsection{Comparisons}

Researchers have broken down specialized advancement and development arrangements in three little open economies: Finland, Sweden and Singapore. Every one of the three economies has changed from relying upon crude material concentrated or work serious creation to exceptionally serious economies with a generally high level of innovative information. We locate some regular determinants to the change, for example, huge interests in physical and human capital and the significance of political or monetary emergencies in compelling through great financial arrangements, yet there are moreover numerous nation explicit viewpoints that have been critical in the various nations. There is significant proof to propose that the human capital needs of the world city vary from what Robinson calls "customary urban areas" or what Markusen and partners term as "second-level urban communities." This way is most eminently burst in the field of world

\footnotetext{
${ }^{33}$ Thangavelu, S. M. (2012). Economic Growth and Foreign Workers in ASEAN and Singapore. The MIT
} Press Journals, 114-136. 
Factors affecting Human capital in Singapore

urban communities, and the progression of talented work by Sassen and with case models (money, law, bookkeeping) gave in the work by Beaverstock and his partners. This spotlight on maker administrations and relocation streams should be coordinated by a going with seeing city-based techniques (Gundlach, 1995) ${ }^{34}$.

While East Asian nations, including South Korea, Taiwan and Singapore, have encountered noteworthy and fast monetary development without popularity based foundations, there are many more economies, including Zaire, Uganda or Haiti, which have crumbled under dictatorship because of the absence of majority rules system and responsibility. Correspondingly, in the event of vote based system, we see instances of nations including Mauritius, who have done well under the majority rules system through Papua New Guinea and Jamaica, have done ineffectively. Consistently improving human capital is essential for monetary development, and Milken calls attention to that China's proceeding and anticipated thriving is determined, in enormous part, by an advancing working class driven by a "constant spotlight on training" (Akpolat, 2014) ${ }^{35}$. He proceeds to exhibit the significance of instruction by contrasting Singapore and Jamaica: both previous British settlements, with populaces of 1.6m and a comparative GDP/capita.

${ }^{34}$ Gundlach, E. (1995). The role of human capital in economic growth: New results and alternative interpretations. Weltwirtschaftliches Archiv, 383-402.

${ }^{35}$ Akpolat, A. G. (2014). The Long-Term Impact of Human Capital Investment on GDP: A Panel Cointegrated Regression Analysis. Sakarya University. 
Factors affecting Human capital in Singapore

The Solow model (1956), a foundation of neoclassical development models, contains two bases: first, consistent state development is autonomous of the investment funds rate; second, the principle wellspring of development is an innovative change to capital aggregation. Be that as it may, the fundamental factor for financial development in these models, in particular innovative advancement, is, in any case, exogenous to the model. In the procedure of imaginative devastation, a formal model, the quality evaluations for an item are displayed as substitutes; in the outrageous case, the different characteristics are impeccable substitutes, inferring that the disclosure of another middle of the road great replaces the former one. Therefore, developments are the wellsprings of continued economic development. As of late, the development execution of the East Asian recently industrialized economies (NIEs) offered to ascend to an expansive and diversified writing targeting clarifying the reasons for such an enduring time of development. Moreover, in the past thirty-five years, Korea, Taiwan, Singapore, and Hong Kong, have reformed themselves from traditionally to moderately present-day and other economies. The enlargement performance of the countries has been unusual in past financial development on the planet up until this point (Lee, 2010) ${ }^{36}$.

Ethnic pay disparity in Singapore has been investigated from the points of view of labourmarket division and human capital. The discoveries of this investigation show that neither one of the perspectives helps clarify ethnic pay imbalance in Singapore. Further, the investigation shows that instructive contrasts among the Chinese, Indians and Malays represent next to no of the

${ }^{36}$ Lee, W. K. (2010). The economic marginality of ethnic minorities: an analysis of ethnic income inequality in Singapore. Asian Ethnicity, 27-41. 
Factors affecting Human capital in Singapore

pay hole. A significant part of the pay contrast is because of separation. The wellspring of this separation lies in the isolation of ethnic minorities in lower-paying employments and occupations overall ventures, reflecting Chinese control in the monetary and political circles. The endeavours to feature a portion of the difficulties looked by the Singaporean economy as a rule and the assembling division specifically. World Economic Forum (WEF). Thus, the quantifiable analysis is applied to display the work of human capital and remote speculation on assembling yield for the period 1980-2004. This shows that a since quite a while ago run relationship exists among the genuine assembling yield per-unit of business, genuine remote speculation per-unit of work and genuine human capital per-unit of work (Mayer, 2001$)^{37}$.

By the 1980s, these nations formed into innovative fare stages as outside multinationals assisted with invigorating monetary development as well as additionally gave benefits as innovation and information overflow. As both economies keep on developing more information serious, open approach is putting a more noteworthy accentuation on building up the framework and human capital important to help imaginative residential limits. In late decades, as a monetary movement in both Singapore and Malaysia has developed more information serious, a more major consideration is being given towards the monetary job of advancement. 
Factors affecting Human capital in Singapore

\section{Chapter 3.0 Methodology}

Based on the previous empirical findings and their interpretations, the proposed study is focused on analyzing the impact of the human capital of Singapore on the economic growth of the country. The initial investigation of defined the use of least squares and other approaches for the investigation of human capital across Singapore based on other factors and relevant confounders. In most cases, the least square estimates have proven relevant in terms of obtaining the desired information across several factors and confounders linked with the relevant outcomes. Nonetheless, the approach of least square regression comes with several errors associated with it, hence proving unreliable on an analysis involving longer periods. In this context, change in analytical approaches proves relevant for coming up with the best solution in terms of linear models to predict changes in the Singapore economy. This calls for panel data analysis for use in evaluating the behaviour of the Singapore economy in terms of economic growth over the respective periods. The significance of the panel data models is based on minimization of the possible errors from any form of regression using robust panel regressors that aid in improved outcomes across different models. The quality of a statistical model is often built on its ability to minimize white noise (errors), and present findings that are unbiased and consistent with the actual situation on the ground. The different regions and sectors that profoundly rely on the quality of the data prove effective in making it ideal for the different components and trends built from any data series. 
Factors affecting Human capital in Singapore

Based on the nature of the data and the assumptions, a pre-requisite condition for a regression analysis/estimation in order to achieve a good economic relationship needs the variables to be cointegrated. In this situation, the residuals will be stationary.

\subsection{Time Series Analysis}

It has been seen in various cases that the econometric data usually exits in three basic structures that are cross-sectional data, panel data and the time series data. The selection of a particular dataset under a given condition will provide reliable statistical figures under given conditions. The relevancy and authenticity of datasets will heavily depend on the nature of the study guided by time factor and the scope of the variables discussed in the study.

Changes in each data series translates to changes in the actual observations, under the assumption that each component in the data is independent of each other, collected from some random samples. The essence of randomness helps to limit pre-disposition by guaranteeing that the consistency inside the datasets is considered for successful deductions and the use of the deduced information results. Time series models comprise of multi-time variates, observed over a long time, with changes in the variable over the period, with a series of changes realized within the course of data collection. The variations are termed as seasonality across the trend, analyzed for different time series models applicable for the respective datasets. On time series data, the time is set differently depending on the software package in use. It allows for unit root tests to investigate 
Factors affecting Human capital in Singapore

the actual trend associated with the time variable, to check whether the time variable is fit for any form of time series modelling.

Most of the datasets with the aspect of linearity across the different variables are often suitable for least square regression since they comprise of one dependent variable that changes based on the variations in the other variables, guided by some linearity assumptions that change over time. Moreover, cross-section data analysis approach and its components can be achieved by running correlation analysis, normality test outlier detection tests and also to alleviate the crosssectional data analysis process by offering relevant and effective propositions with respect relevant model assumptions over expected periods. In most cases, such models come with greater provisions as they provide room for multiple models because time series approach or models in econometrics are multivariate. As opposed to the case with time-series data that only involve one time variable that change across the entire series. Although the study uses the time series approach in the given context, there may arise the concerns of the time series analysis to be non-stationary endangering the reliability of the results obtained. The obtained results can be minimized by detrending if there is a deterministic trend in the analyzed data. Moreover, the non-stationary time series may combine stochastic and deterministic trends at the same time. This may lead to creating unexpected and misguiding results. To avoid such results differencing and detrending factors should be applied because the differencing factor will minimize the trend in the variance, whereas the detrending factor will remove the deterministic trend, thus giving desired outcomes. Ultimately, board Data exudes from longitudinal information that includes a few factors over some 
Factors affecting Human capital in Singapore

significant time-frame periods. Because of the probability of a high impact of the error, the panel data analysis may not prove to be an effective test to analyze the impact of the economic growth of Singapore over time. Majority of the considered variables are showing a likelihood of high error factors when it comes to modelling with the use of least square regression methods and tests. The efficiency of Ordinary Least Square regression is an apprehension factor for majority factors because this particular method is not viable to associate the accuracy to that of the analysis. Moreover, the panel data analysis contains both the cross-sectional data and the time series data in two distinct directions with an intent to achieve the desired analytical objectives over the respective analytical periods. The merit of such data analysis is associated with the quality control aspects in terms of standard error mitigation and minimization that orient from both the panel data and timeseries data analysis.

In the case of this study, OLS regression models prove appropriate to understand the aspect of economic growth in Singapore from past time variables. The advantage of this move is also extended to the inclusion of more linear variables to develop an appropriate relationship.

Ordinary least squares regression was used for this study. The analysis is often defined as a multidimensional and econometric approach in which the data is collected for more than two dimensions defined concerning time, type and other relevant dimensions. The viability of these provisions creates sense out of data, with the different components associated with data. The OLS regression models translate into some regression model with both the dependent variable and a series of independent variables observed over some time. In most cases, the error term is also 
Factors affecting Human capital in Singapore

termed as an important component of the panel regression model, as it measures the levels of efficiency associated with the resultant model in answering the research hypothesis. However, $10 \%$ and $1 \%$ levels of significance also prove appropriate since they are statistically viable in making desired inferences.

\subsection{Data Sources}

The data used was collected from the Groningen Growth and Development Center (Penn World Table) website, from 1950 to 2017 on the human capital data. The data was defined in a numerical (ratio) scale, within varied intervals and downloads adopted to examine changes in the respective datasets employed. These variations implicate the possibility of differences in changes associated with human capital development and its respective associative factors. Most of these observations were enshrined on datasets downloaded individually from the website to meet the aims of the observations with respect to the relevant data in place. Data cleaning was also adopted with reasonable statistical approaches implicated on the series of variables employed to ease identification of the patterns and present the best solutions for the human capital problem in Singapore. The essence of data cleaning was done to ensure that the extreme observations that might interfere with the quality of the findings in relation to meeting the actual objectives of the study. 
Factors affecting Human capital in Singapore

\subsection{Variables}

- $\mathrm{Y}=\mathrm{hc}$, defined as the human capital index measured based on the years in school and returns to education as per the Human capital definition in PWT9

- $\mathrm{X} 1=\mathrm{pop}$, defined as population of persons in Singapore measured in millions

- $\mathrm{X} 2=\mathrm{emp}$, defined as the number of persons engaged (in millions)

- $\mathrm{X} 3=$ avh defined as the average annual hours worked by the engaged persons

- Granger casualty and Johansen Cointegration tests were used to test for the association between human capital and the other variables across the study. 
Factors affecting Human capital in Singapore

\section{Chapter 4 Data Findings}

The main objective of this study is to analyze the impact of human capital on the economic growth of Singapore based on the past data. Moreover, the term Correlation is also known as Pearson correlation which shows the association among variables in a study. Consequently, the Pearson correlation assists the study to find out relationship or correlation among two variables and either this is falling in the range of Pearson correlation or not. It is very necessary to know the range of correlation which provides the strength to the correlation among two variables. The range of Pearson correlation comprises the scale from -1.00 to 1.00 . However, the range 1.00 means that the variables are perfectly and positively correlated to each other. Likewise, the variables considered as perfectly negative correlated when the range of correlation is -1.00 . At the range of 0 , there is no association among selected variables.

\section{Table .1 Correlation}

\section{Correlations}

\begin{tabular}{ll|l|l|l|l|l} 
& rgdpe & rgdpo & pop & emp & avh & hc \\
\hline Rgdpe & $\begin{array}{l}\text { Pearson } \\
\text { Correlation }\end{array}$ & .996 & $.967^{* *}$ & $.974^{* *}$ & $.360^{* *}$ & $.964^{* *}$ \\
$\begin{array}{l}\text { Sig. } \\
\text { tailed) }\end{array}$ & $(2-.000$ & .000 & .000 & .006 & .000 \\
\hline $\mathrm{N}$ & 58 & 58 & 58 & 58 & 58
\end{tabular}


Factors affecting Human capital in Singapore

\begin{tabular}{|c|c|c|c|c|c|c|}
\hline \multirow[t]{3}{*}{ Rgdpo } & $\begin{array}{l}\text { Pearson } \\
\text { Correlation }\end{array}$ & $1 * *$ & .962 & $.972^{* *}$ & $.321^{* *}$ & $.955^{*}$ \\
\hline & $\begin{array}{l}\text { Sig. } \\
\text { tailed) }\end{array}$ & & .000 & .000 & .014 & .000 \\
\hline & $\mathrm{N}$ & 58 & 58 & 58 & 58 & 58 \\
\hline \multirow[t]{3}{*}{ Pop } & $\begin{array}{l}\text { Pearson } \\
\text { Correlation }\end{array}$ & $.962^{* *}$ & $1 * *$ & .992 & $.502^{* *}$ & $.984^{* *}$ \\
\hline & $\begin{array}{l}\text { Sig. } \\
\text { tailed) }\end{array}$ & .000 & & .000 & .000 & .000 \\
\hline & $\mathrm{N}$ & 58 & 58 & 58 & 58 & 58 \\
\hline \multirow[t]{3}{*}{ Emp } & $\begin{array}{l}\text { Pearson } \\
\text { Correlation }\end{array}$ & $.972^{* *}$ & $.992^{* *}$ & $1 * *$ & .430 & $.985^{* *}$ \\
\hline & $\begin{array}{l}\text { Sig. } \\
\text { tailed) }\end{array}$ & .000 & .000 & & .001 & .000 \\
\hline & $\mathrm{N}$ & 58 & 58 & 58 & 58 & 58 \\
\hline \multirow[t]{3}{*}{ Avh } & $\begin{array}{l}\text { Pearson } \\
\text { Correlation }\end{array}$ & $.321^{* *}$ & $.502^{*}$ & $.430^{* *}$ & 1 ** & .482 \\
\hline & $\begin{array}{l}\text { Sig. } \\
\text { tailed })\end{array}$ & .014 & .000 & .001 & & .000 \\
\hline & $\mathrm{N}$ & 58 & 58 & 58 & 58 & 58 \\
\hline $\mathrm{Hc}$ & $\begin{array}{l}\text { Pearson } \\
\text { Correlation }\end{array}$ & $.955^{* *}$ & $.984^{* *}$ & $.985^{* *}$ & $.482^{* *}$ & $1 * *$ \\
\hline
\end{tabular}


Factors affecting Human capital in Singapore

\begin{tabular}{l|l|l|l|l|l|}
\hline $\begin{array}{l}\text { Sig. } \\
\text { tailed })\end{array}$ & $(2-.000$ & .000 & .000 & .000 & \\
\hline $\mathrm{N}$ & 58 & 58 & 58 & 58 & 58 \\
\hline
\end{tabular}

As it has been mentioned earlier that human capital is taken as $\mathrm{Y}$ variable and other variables are taken as X's. In the above-mentioned table, the value of the human capital index is $(\rho=0.964)$, which shows a strong positive relationship with real side GDP expenditure (RGDPE). As we know if the variable has greater value than 0.5 it means it has a strong correlation. Moreover, it shows that the real GDP expenditure and human capital index are strongly correlated and (RGDPE) had a higher chance of increasing the human capital index within the country during the past years. The next variable is outside real GDP (RGDPO), and the value of this variable is $(\rho=0.955)$, which again lies in the strong correlation. It means that there is a strong positive relationship between outside real GDP and the human capital index. The findings showed that an increase in human capital index measured based on the years in school and returns to education as per the Human capital definition may be attributed to outside-side real GDP. Furthermore, the next variable is population in persons in Singapore (POP). The value of this variable is $(\rho=0.984)$ which depicts that population in persons and human capital index are strongly correlated with each other. In addition to it, the population of persons in Singapore measured in millions (POP) and the human capital index measured based on the years in school and returns to education as per the Human capital definition in PWT9 (HC) had a positive relationship with each other. The findings showed that an increase in human capital index measured based on the years in school and returns to education as per the Human capital definition in PWT9 (HC) may be attributed to growth in 
Factors affecting Human capital in Singapore

outside-side real GDP. For the next variable, which is the number of persons engaged (in millions) the value is $(\rho=0.985)$ which again depicts the strong relationship between the human capital index and number of persons engaged (EMP). It is clearly seen from the correlation that the number of persons engaged (in millions) (EMP) and human capital index measured based on the years in school and returns to education as per the Human capital definition in PWT9 (HC) had a positive relationship with each other. This showed that a decline in the human capital index measured based on the years in school and returns to education as per the Human capital definition in PWT9 (HC) was linked to rise in number of persons engaged (in millions) (EMP). The next variable is (AVH), which is the average annual hours worked by the engaged persons. The value of this variable is $(\rho=0.482)$, which lies in the range of medium positive correlation which $(0.30-0.49)$. Additionally, it also shows a positive relationship with the human capital index. Moreover, the average annual hours worked by the engaged persons $(\mathrm{AVH})$ and human capital index measured based on the years in school and returned to education as per the Human capital definition in PWT9 (HC) had a positive relationship with each other. The analysis implies that a rise in the average annual hours worked by the engaged persons $(\mathrm{AVH})$ on the human capital index. So according to the findings of correlation, it has been revealed that population, the number of people engaged and the average annual hours worked by engaged persons had a significant positive effect on the human capital index. 
Factors affecting Human capital in Singapore

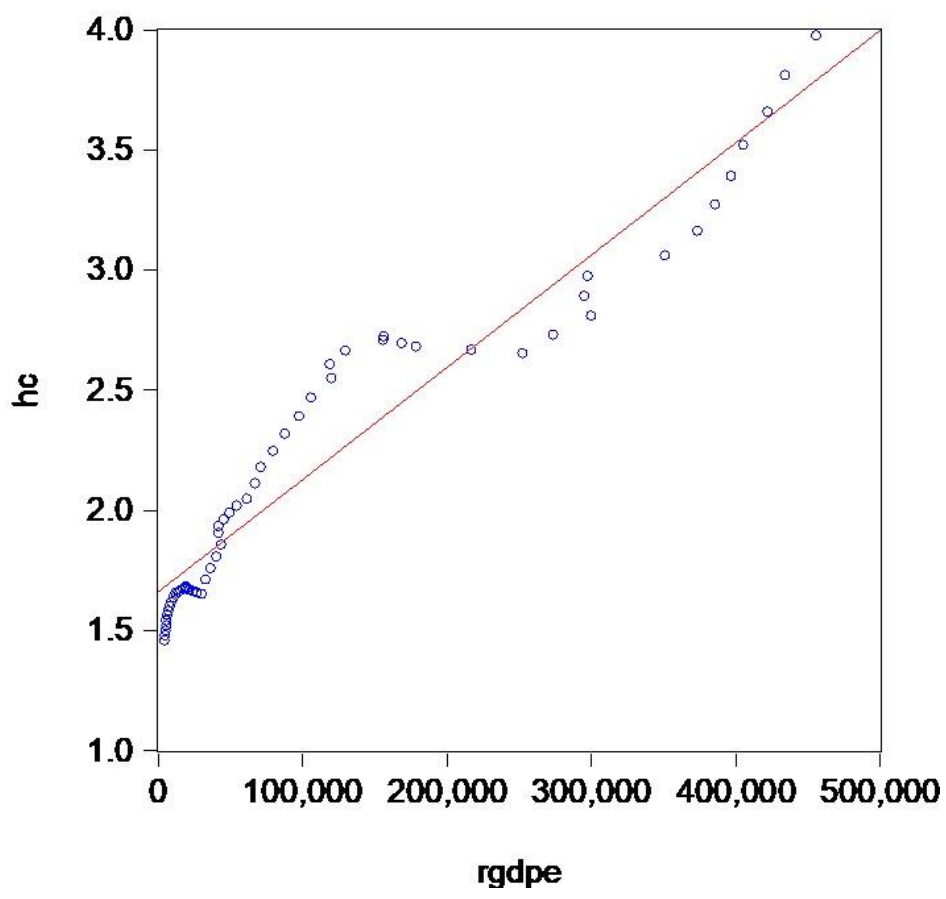

Figure.1 Scatterplot of (RGDPE) expenditure side real GDP and human capital index

The measure implied that a rise in human capital index measured based on the years in school and returns to education as per the Human capital definition in PWT9 (HC) was as a result of a rise in the values associated with expenditure side real GDP. 
Factors affecting Human capital in Singapore

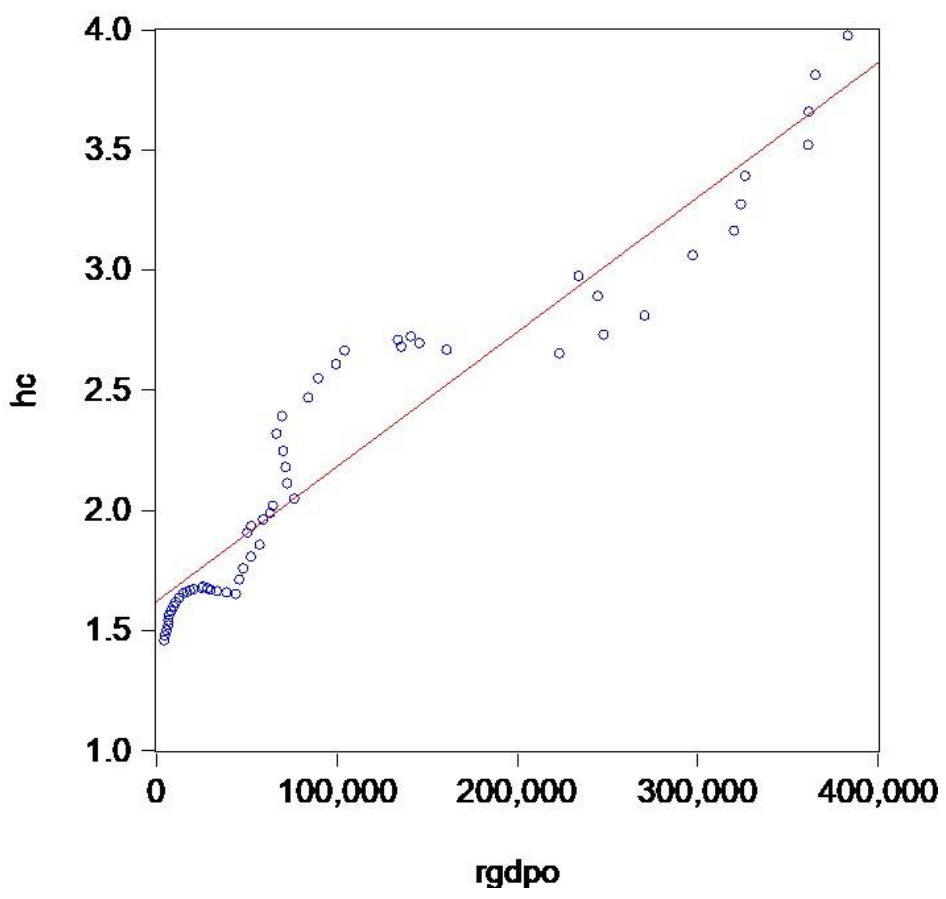

Figure.2 Scatterplot of (RGDPO) outside-side real GDP and human capital index

On the findings, (RGDPO) outside-side real GDP had a positive relationship with the human capital index. The pattern indicates that a rise in the values of human capital index translates to a rise in the outside-side real GDP. 
Factors affecting Human capital in Singapore

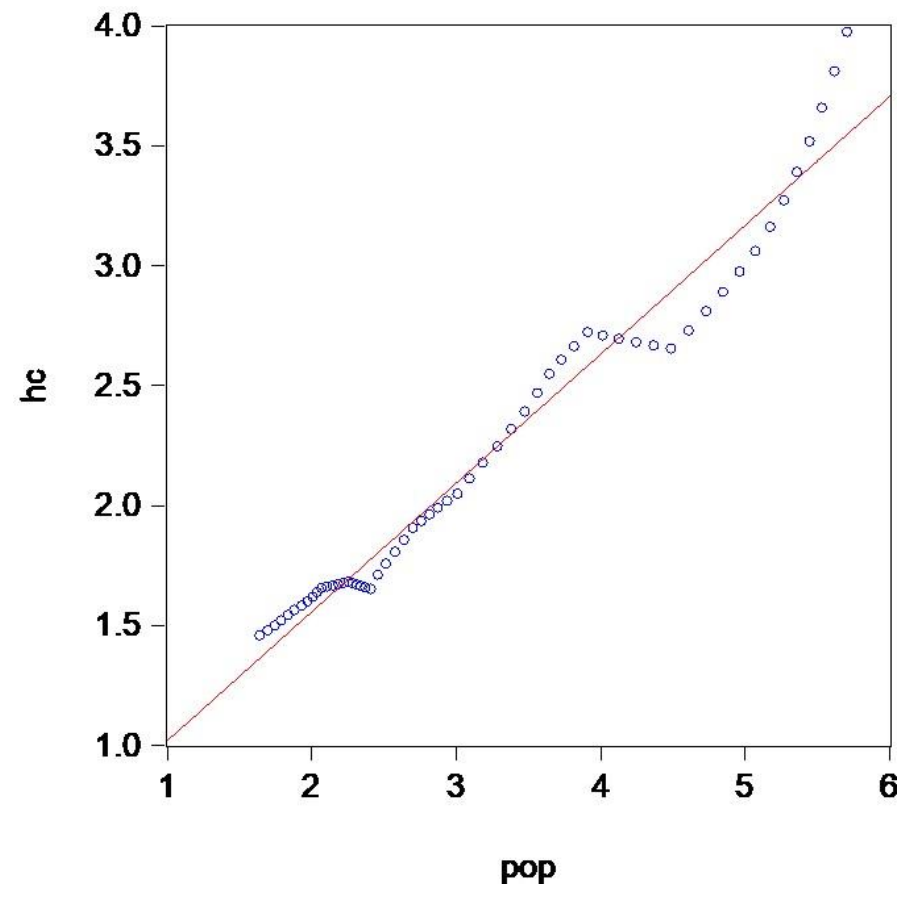

Figure.3 Scatterplot of population of persons in Singapore measured in millions (POP) and human capital index

The analysis reveals that a rise in the human capital index emanates from a rise in population of persons in Singapore measured in millions (POP).

\section{Chapter.5 Discussion}

After the data analysis, this chapter will further explain and describe the main findings of the study related to the factor affecting human capital of Singapore. However, it is believed that the members of society are capable of performing various productive tasks to contribute to the economic development of the country. Countries with a good human capital resource can increase its labour productivity and subsequently progress economically (Dinda 2008). The theory of 
Factors affecting Human capital in Singapore

human capital provides a prism to study and understand a certain society, community, or a country through its socio-economic changes to accumulate wealth (Sweetland 1996). The total investment made on individuals to equip them with knowledge and skills for innovation, development, and production of new ideas, products, and services accounts for human capital deployment. Such kind of investments comprises the advancement of individual education, skills, training, talent, and experience to develop more skilled, and productive individuals. Subsequently, productive individuals (labour and workers) earn higher values and more lucrative labour market. Moreover, education is considered a variable that influences human capital. Investment in education is the reason why people invest in themselves today, to ensure their future capacity, skill, and knowledge makes their services more valuable and lucrative. People are the most valuable resource available to the Singapore economy in particular and the world economy in general. For Singapore, it is the most important strategic asset (Osman-Gani, 2004). At the national level, strategies to improve human resource have been reviewed time and again to ensure its compatibility with economic growth goals. Moreover, the country's strategic economic plans hold human resource development at the highest priority. Since Singapore holds the top position in the Human Capital Index in Asia, its human resource is regarded as one of the best workers in the world. Furthermore, this recognition creates the potential for work outside of Singapore. The skilled workforce of Singapore can be exported to other countries, and in doing so, the exported workforce will send back remittances which is productive for the economic growth of Singapore. Koh (2012) suggest that Singapore has tremendous national spending on education. The country spent around SGD 10.91 
Factors affecting Human capital in Singapore

billion in 2011. However, the amount spent on education is less than that spent on military and defence each year SGD 12.08 billion.

Moreover, in 1965, after independence, the economy of Singapore is at the lowest level later, the economy of Singapore increased gradually from low to high income developed economy. The vivid example of Singapore economic growth is the value of HDI that is 0.889 in 2011. Singapore faced many challenges at the initial stage because the majority of the labour force are uneducated and unskilled, which is consider as a curse for the country. However, to improve growth rate education system is improvised to make labour force self-resilient. Over time the labour force of Singapore gained valuable skills such as in the year 2012,29.4 percent of labour force gain tertiary education level, 49.9 percent of labour have gained access to secondary level education, and 20.7 percent of the total labour force have got primary education (Maitra, 2016). Hence, the statistics clarify how much human capital play an important role in order to strengthen the economy. Additionally, Asteriou and Agiomirgianakis (2001) found that the development of human capital is an important element for the economic growth of a country that includes health, education and per capita income.

However, a rise in training straightly affects human capital stock, and that age is directly related to human capital as different age clusters rise human capital. It was also set that human capital stock depends upon the transmission of the population between urban and rural segments.

On the other hand, the effect of the Capital per Active worker theoretically rises the overall Revenue per Effective worker. Moreover, Singapore appealed to labour-intensive businesses and 
Factors affecting Human capital in Singapore

employed adequate teachers to deliver training for the whole inhabitants and support them with the necessary expertise to make them employable in those businesses. In 1985-2005, Singapore focused on improving the staffing rate and reducing the failure rate. In the period of changing the country into a knowledge-based economy, in 1995-1999, the administration is keen on rising intellectual abilities such as critical and creative philosophy. The administration also regionalized institutes gave them more preference to inspire improvement and offer a free atmosphere for scholars to content their wellbeing and skills (EFA: Singapore, 2015).

However, in the case of Singapore at the initial stage, the investment in human capital fails to raise economic growth, but the progress of labour force in the economy raised year by ear and marginal productivity of labour become positive. In addition to this, the main reason of capital formation in Singapore is strengthening their economy so for this purpose human development strategies are aligned with national and economic policies to make the proper adjustment with time to time. However, the integration of different national interest policies helps Singapore to develop their human capital at the highest level, and thus they improved their per capita income, which further leads to increment in the real GDP of the country. In 2000, the Skills Development Tariff was reread to offer more resources for skills advancement. The Skills Re-development Programme (SRP), which started with the manufacturing sector, was extended to support worker training in service sectors. Besides, the government-assisted in raising funds and gave a matching grant to the NTUC's (National Trade Union Congress) Education and Training Fund (N-ETF). A Local Care 
Factors affecting Human capital in Singapore

program was also launched, aimed at helping reduced and jobless labour force skill to fill job vacancies in the local housekeeping industry (Osman-Gani, 2004).

In addition, as it has been mentioned earlier that the basic aim of this research is to determine the effects of human capital on the GDP growth of Singapore. The human capital index is an important factor to measure the productivity of human resource in future. Furthermore, human capital means to provide opportunities to the individuals of the country to make them skill full so that they can contribute to economic development. There are many studies performed to check the relationship between the economic growth of a country and its human capital index. Moreover, there are certain factors which directly affects the human capital index and consequently to economic growth. In addition to it, the study has analyzed the effects of population, the number of people engaged and the average annual hours worked by engaged persons on the human capital index. As discussed earlier, four main variables were taken for this study. The human capital index is taken as the dependent variable and population of persons (POP), engaged persons (EMP) and the number of average hours are taken as independent variables. As reflected in correlation analysis, the study has found the positive relationship between all these variables because the values of these variables lie in the range of strong positive correlation.

Nonetheless, human capital accumulation has long been stressed as a pre-requisite for economic growth. An additional role for human capital may be as an engine for attracting other factors, such as physical capital, which also contributes measurably to per capita income growth (Benhabib, 1994). Nevertheless, the impact of human capital on economic growth has also received 
Factors affecting Human capital in Singapore

great attention in recent years. There are two major approaches to the question of how human capital affects the economic growth of an economy. The first is to introduce human capital as an input in the production process. This implies that there exists a correlation between human capital and growth of output. The second approach follows that they consider human capital as a source of productivity growth (Chaudhry, 2010).

Review of national skill development efforts in Singapore, Ogunade (2011) proposed a distinct strategy to facilitate the development and strengthening of human capital in developing states. However, due to existing poverty, disease, and deprivation, the people of the developing world are facing hard challenges to produce innovatively. However, Singapore is an exception to the leading human capital index in Asia, and creating attractive investment opportunities for foreign investors. Due to its highest human capital ranking, investors feel comfortable while investing in Singapore, because they know that the human capital in Singapore is skilled, educated, and experienced enough to progress economically. The most significant feature of Singapore's Human Capital Development is a state-led Strategy focusing on the coordination of demand and supply of skills in an open competitive environment. The state-led strategy is similar to the strategy adopted by South Korea which focused on the skill development of its population to meet the demands of its state-run industries.

Conversely, according to Koh (2012) there are also concerns regarding the growing trend among Singapore's student population of going abroad for further studies and eventually end up working for the host country, creating a brain drain situation for their home country. It is a problem 
Factors affecting Human capital in Singapore

for countries when skilled, and educated individual leaves their home country in search of better economic and social opportunities elsewhere. According to Tyson (2019), the brain drain situation is specifically crucial for economies like Malaysian and Singapore. Its innovative, driven economies will be badly affected by the brain drain situation. The countries may be politically divided; however, they are economically interlinked. Singapore is a city-state which frequently relies on the imported workforce from the East, South, and Southeast Asia for the past 50 years. Malaysia and Singapore are continuously and competitively engaged in acquiring talented individuals with high skills, well educated, and increasingly innovative mindset. Moreover, bilateral estimation of migrant stock reveal that more than 1.1 million people migrated from Malaysia to Singapore. The World Bank collects the data. On the other hand, over 81,000 people migrated from Singapore to Malaysia. From these findings, it is necessary to conclude that there is more flow of population migration from the Malaysian side towards Singapore. The population migration from Singapore to Malaysia is less at around 81,000 people only. This kind of situation proves beneficial for Singapore's human capital development. Moreover, the total population export from Singapore is less than its population import. So the study can rule out the concerns of brain-drain in Singapore. Singapore exported exactly 337.924 migrants in 2017. Most of them went to Malaysia, Australia, UK, and the US. In exchange, Singapore received exactly, 2,623,404 people from around the world. Majority of the migrants exported to Singapore in 2017 belonged to Malaysia with more than a million migrants. China was in second place, which exported over 400,000 people to Singapore. The research by Ho \& Tyson (2011) finds that Malaysia is experiencing brain drain situation for decades due to its highly skilled labour force migrating to 
Factors affecting Human capital in Singapore

other countries. The major challenge comes with the major proportion of Malaysian skilled individuals migrating to Singapore.

According to Huang et al. (2002), economic development in Singapore is due to foreign direct investments by Multinational Corporations (MNCs) operating in the country. Due to the introduction of MNC, the local business has turned to adopt new strategies to meet with the increasingly competitive business environment. The MNCs have introduced Singapore's human capital market to a new capital, technology, and managerial procedures. Moreover, the foreign direct investments are beneficial to the local economy by creating economic opportunities for the local communities and utilizing the human capital.

Research by Anwar (2008) regards foreign direct investment as one of the major drivers of Singapore's manufacturing sector, and human capital development. The economic growth of Singapore is largely dependent upon its manufacturing sector, which runs on foreign investment. The secret to this growth is Singapore's prominence of highly productive human capital. According to statistical findings, all economic indicators selected in the study to assess human capital indicate a positive correlation with human capital. However, the study did not recognize the role of technology in the assessment of factors that influence human capital development in Singapore.

Energy is one of the essential components for technological, industrial, and subsequent economic advancement. Study of a causal relationship between economic growth and human capital finds that energy has a significant granger causal impact on the human capital of Singapore (Fang et al., 
Factors affecting Human capital in Singapore

2020). Moreover, the study also finds that human capital has a granger causal impact on physical capital in Singapore. Research by Litsareva (2017) regards Singapore as one of Asia Pacific's fastdeveloping country among others including South Korea, Malaysia, and Thailand. In short, the factors the contribute to the human development of Singapore are more than just employment, population, economic growth, and education. External economic factors such as foreign direct investments, migration, and energy also play an instrumental role in human development of Singapore.

\section{Chapter 6. Conclusion}

The proposed study focused on the impact of Human capital on the economic growth of Singapore. The study based on the discussed objectives of the research and the parameters to profoundly analyze and evaluate the critical factors that contribute to the human capital index. Various researches and studies have shown that human capital has a robust effect on the economy of a country. The study also found out that the number of working hours have a significant impact on the human capital index and this particular progression leads to the economic wellbeing of a country. The study analyzed and evaluated broad factors in studying the impact that human capital has on the economic growth of Singapore over the past years. 
Factors affecting Human capital in Singapore

The study shows that Singapore has been enlisted in the list of the world's thirteen most promising countries that have taken progressive and productive steps to strengthen their economic growth with effective implementations towards economic development, workforce wellbeing and profitable state policies. The study has aimed to focus on the significance of economic growth under the umbrella of human capital growth. It has been discussed and agreed that the economic stability and progress of Singapore is also based on the financial development strategies that have retained with the human capital of the country and the work power business structure under specific econometric strategies. It has been indicated that both human capital and business activities add up to the financial development of the country, which paves the way towards a strengthened economic growth. Over the past three decades, the success behind the economic prosperity of Singapore is because of a meaningful association of the human capital with the business entities in maximizing the financial stability thus circulating the economic cycle of the country. Workforce conditions and associated practices of Singapore has shown that the government has made a chain structure that facilitated the key areas for development. Some of the crucial aspects that the country considers as part of their progressive and profitable economic strategy include various working standards that have proven to be effective in terms of effective work delivery and the enhanced work practices with more authentic and timely cooperation among departments within the country. With the help of previous researches and the statistical data analysis, it has also been shown in the study that the human capital considered to be the main driving agent behind the monetary developments of a country and Singapore is one among those countries that have effectively implemented effective social development strategies to enhance its human capital structure. The study also poses that 
Factors affecting Human capital in Singapore

there are various factors that the country addressed with utmost priority in developing the framework for an excelling economic growth. The comparative analysis of the economic development structures of three countries that were compared to that of Singapore in the study reveals that all of these countries have successfully shifted from traditional work paradigm to innovative work practices that helped the government in gaining the economic excellence over the period of time.

With the help of the panel data analysis, time series analysis and OLS regression methods, the study showed various variable and independent factors that have direct or indirect control on the economic growth of Singapore. The past data was obtained from the given sources in the study for the analysis. The results obtained from the correlation and descriptive analysis showed that the real GDP expenditure (RGDPE) of Singapore and the human capital index have a strong correlation which proves that the real GDP expenditure of the country had enhanced the human capital index of the country over the past years thus contributing to the economic growth of the country (OECD, 1999). The correlation tests of various variables such as population, number of engaged people and the average annual working hours have strengthened the human capital index of the country over the years that have been regarded as few of the prominent factors in the economic growth of the country. The research with the help of the Granger Casualty tests and the Johansen Cointegration tests brought various associations between the human capital index and the selected variables. The study further revealed that (RGDPE) government of Singapore made robust investments in the adult and student skill and educational development programs in the 
Factors affecting Human capital in Singapore

pursuit of a high human capital index (OECD, 1999). Furthermore, various comparisons, analysis and statistical data of the past years have shown that Singapore has evolved as a country with an exceptional human capital index in the continent of Asia and has also proven itself to be an excellent platform for the future business investments that will further brace the economic situation of the country. The study also reveals that economic progression and development is highly dependent on the Skilled and experienced workforce.

Based on the analysis, discussions and previous researches, it has been seen that incorporation of various educational, professional and vocational training workshops and strategies are the core requirements to enhance the economic stability of any country. Maximum interaction and participation of the state authorities in such programs will help in creating an educated and professional workforce that will ensure work and productivity optimization. The study will be a valuable source of information for future researches in analyzing the impact of human capital strategies on the economic performance of a country. Furthermore, the study will also enable students and professionals in understanding the key concepts that are associated with the human capital index and various approaches that can be initiated to facilitate economic activities. 
Factors affecting Human capital in Singapore

\section{References}

1. Akpolat, A. G. (2014). The Long-Term Impact of Human Capital Investment on GDP: A Panel Cointegrated

a. Regression Analysis. Sakarya University, .

2. Almendarez, L. (n.d.). Human Capital Theory: Implications for Educational Development.

3. Anwar, S. (2007). Manufacturing Sector Growth: A Case Study of Singapore. Global Economic Review,

a. 381-396.

4. Anwar, S. (2008). Foreign investment, human capital and manufacturing sector growth in Singapore.

5. Journal of Policy Modeling, 447-453.

6. Briscoe, R. A. (2004). The impact of human capital on economic growth: a review. Jour .

7. Chan, A. M. (2009). Trends and challenges of developing human capital in Singapore: an analysis of current practices and future potentials. Human Resource Development International .

8. Eng, V. M. (2010). Financial development and economic growth in Singapore: demand-following or supply-leading? Applied Financial Economics , 391-404.

9. G. Agiomirgianakis, D. A. (2002). Human capital and economic growth revisited: A dynamic panel data study. International Advances in Economic Research , 177-187.

10. Garcia-Zamor, A. S.-C. (2017). Influence of Human Capital on Economic Growth: A Comparative Analysis of Education Development in Kazakhstan, South Korea, Singapore and Malaysia. Journal of

11. Public Administration and Governance.

12. Ge, K. C. (2011). Education and human capital management in a world city: the case of Singapore. Asia

13. Pacific Journal of Education , 263-276.

14. Gerald Z.D. Huang, M. H. (2002). MNCs in Singapore. Benchmarking: An International Journal.

15. Gomes, L. (2003). The Economics and Ideology of Free Trade: A Historical Review. Department of 16. Economics. 
Factors affecting Human capital in Singapore

17. Gopinathan, S. (2006). Preparing for the Next Rung: economic restructuring and educational reform in

18. Singapore. Journal of Education and Work , 295-308.

19. Gundlach, E. (1995). The role of human capital in economic growth: New results and alternative interpretations. Weltwirtschaftliches Archiv , 383-402.

20. Huff, W. G. (1997). The economic growth of Singapore: Trade and development in the twentieth century.

a. Cambridge University Press.

21. JUSTMAN, M. G. (2002). Education, Social Cohesion, and Economic Growth. THE AMERICAN ECONOMIC

22. REVIEW.

23. Koh, A. (2012). Tactics of Interventions: Student Mobility and Human Capital Building in Singapore.

24. Higher Education Policy, 191-206.

25. Kuruvilla, S. (2006). Sustainable workforce development: the paths of Singapore and India. School of

26. Industrial and Labor Relations.

27. LEE, C. G. (2008). TOURISM AND ECONOMIC GROWTH: THE CASE OF. Regional and Sectoral Economic

28. Studies .

29. Lee, W. K. (2010). The economic marginality of ethnic minorities: an analysis of ethnic income inequality

a. in Singapore. Asian Ethnicity , 27-41.

30. Leeuwen, P. F. (2008). Human Capital and Economic Growth in Asia 1890-2000: A Time-series Analysis *.

31. Asian Economic Journal, 225-240.

32. Magnus Blomstrom, A. K. (2002). GROWTH AND INNOVATION POLICIES FOR A KNOWLEDGE ECONOMY:

a. EXPERIENCES FROM FINLAND, SWEDEN, AND SINGAPORE. Stockholm School of Economics.

33. Maitra, B. (2016). Investment in Human Capital and Economic Growth in Singapore. SAGE Journals,

a. $425-437$.

34. Mayer, J. (2001). TECHNOLOGY DIFFUSION, HUMAN CAPITAL AND ECONOMIC GROWTH IN

35. DEVELOPING COUNTRIES. UNITED NATIONS CONFERENCE ON TRADE AND DEVELOPMENT. 
Factors affecting Human capital in Singapore

36. Maynes, G. (2011). Human capital accumulation : a comparative study of Singapore and Malaysia - 1975 to 2006. Economics, Finance and Marketing, RMIT University .

37. Nguyen, T.-A. (2009). Sources of Economic Growth: Physical capital, Human Capital, Natural Resources, and TFP. Economics and Finance.

38. Osman-Gani, A. M. (2004 ). Human Capital Development in Singapore: An Analysis of National Policy

39. Perspectives. Advances in developing human resources .

40. Paul A. David, N. S. (1975). Technical Choice Innovation and Economic Growth: Essays on American and

41. British Experience in the Nineteenth Century. Cambridge University Press.

42. Raut, A. L. (1997). Complementarities between Exports and Human Capital in Economic Growth:

43. Evidence from the Semi-industrialized Countries. Economic Development and Cultural Change .

Rodriguez-Clare, P. J. (1997). Economic growth: A review essay . Journal of Monetary Economics, 597-

a. 617.

44. Sam, S. A. (2008). Services sector growth in Singapore. Singapore Institute of Management.

45. Sclafani, S. (2008). Rethinking Human Capital in Education: Singapore as a Model for Teacher

46. Development. Aspen Institute.

47. Tan, A. M. (2006). Human resource development: the key to sustainable growth and competitiveness of

48. Singapore. Human Resource Development International , 417-432.

49. Tan, K. W. (2008). Nonmonotonic relationship between human capital and unemployment: an exploratory study with empirical evidence on Singapore. Applied Economics Letters , 1177-1185.

50. Thangavelu, S. M. (2012). Economic Growth and Foreign Workers in ASEAN and Singapore. The MIT

51. Press Journals , 114-136.

52. Wong, P.-w. L.-c. (1981). Human Capital and Inequality in Singapore. Economic Development and

53. Cultural Change.

54. ZHENG FANG, Y. C. (2017). HUMAN CAPITAL AND ENERGY: A DRIVER OR DRAG FOR ECONOMIC

55. GROWTH . The Singapore Economic Review . 
Factors affecting Human capital in Singapore 